\title{
Caregivers' burden in patients with COPD
}

This article was published in the following Dove Press journal:

International Journal of COPD

12 February 2015

Number of times this article has been viewed

\author{
Marc Miravitlles' \\ Luz María \\ Peña-Longobardo \\ Juan Oliva-Moreno ${ }^{2}$ \\ Álvaro Hidalgo-Vega ${ }^{2}$ \\ 'Pneumology Department, University \\ Hospital Vall d'Hebron, Ciber of \\ Respiratory Diseases (CIBERES), \\ Barcelona, Spain; ' ${ }^{2}$ Faculty of Law \\ and Social Sciences, University \\ of Castilla-La Mancha,Toledo, Spain
}

Correspondence: Marc Miravitlles Pneumology Department, Hospital Universitari Vall d'Hebron, Pg Vall d'Hebron I19-129, 08035 Barcelona, Spain

Tel +34 932746083

Fax +34932746083

Email mmiravitlles@vhebron.net
Objective: Chronic obstructive pulmonary disease (COPD) is a very prevalent and invalidating disease. The aim of this study was to analyze the burden borne by informal caregivers of patients with COPD.

Methods: We used the Survey on Disabilities, Personal Autonomy, and Dependency Situations (Encuesta sobre Discapacidad, Autonomía personal y Situaciones de Dependencia [EDAD]2008) to obtain information on the characteristics of disabled individuals with COPD and their caregivers in Spain. Additionally, statistical multivariate analyses were performed to analyze the impact that an increase in dependence would have on the problems for which caregivers provide support, in terms of health, professional, and leisure/social dimensions.

Results: A total of 461,884 individuals with one or more disabilities and with COPD were identified, and 220,892 informal caregivers were estimated. Results showed that $35 \%$ of informal caregivers had health-related problems due to the caregiving provided; $83 \%$ had leisure/social-related problems; and among caregivers of working age, 38\% recognized having profession-related problems. The probability of a problem arising was significantly associated with the degree of dependence of the patient receiving care. Caregivers of patients with great dependence showed a $39 \%$ higher probability of presenting health-related problems, $27 \%$ more professional problems, and $23 \%$ more leisure problems compared with those with nondependent patients.

Conclusion: The results show the large impact on society in terms of the welfare of informal caregivers of patients with COPD. A higher level of dependence was associated with more severe problems in caregivers, in all dimensions.

Keyword: informal care, chronic care, disease burden

\section{Introduction}

Noncommunicable diseases produced more than 300,000 deaths in Spain in 2008, representing $80 \%$ of the total deaths in that period. From 1993 to 2006, chronic disability in Spain increased by $2 \%$. It is found in $22.5 \%$ of the population between 65 to 69 years of age and in up to $65 \%$ of those older than 80 years, ${ }^{1}$ being $10.5 \%$ more frequent in women than in men. ${ }^{2}$

Chronic obstructive pulmonary disease (COPD) is a progressive disease characterized by progressive shortness of breath and severe limitations in daily life activities. ${ }^{3}$ This disease ranks fifth among the main causes of mortality and is also listed among the ten main causes of disability-adjusted life years. ${ }^{4}$ The chronic course of COPD is aggravated by the occurrence of episodes of acute exacerbation with a high burden of morbidity and mortality. ${ }^{5}$ Furthermore, the frequency of exacerbations increases as the disease progresses to moderate and severe stages and is associated with impaired physical, social, psychological, and cognitive status of patients, that is, health-related quality of life. ${ }^{6}$ COPD causes considerable distressing symptoms, reduced self-care capability, anxiety/panic, and depression..$^{6-9}$ In general, patients with 
COPD face functional physical limitations and often require the help of others at certain times in their lives. ${ }^{8,9}$

Most people with COPD live in a community in which relatives and friends (informal caregivers) are the main providers of care and are required to be prepared for lengthy hands-on care in the management of the later stages of the illness. ${ }^{8,10}$ Caregiving is physically, emotionally, and financially demanding work, which induces high caregiver burden, and which may be associated with a decrease in their quality of life and have a significant impact on their health. ${ }^{10-12}$

However, there is no clear evidence suggesting the relationship between the degree of dependency and the problems related to nonprofessional care of people with COPD in different dimensions. Therefore, it is important to learn more about the characteristics and problems of caregivers in order, to optimize the design and implementation of programs of support for reducing negative impacts on life satisfaction. The main aim of our study was to analyze the burden that the nonprofessional care of patients with COPD represents in terms of the well-being of these informal caregivers, distinguishing between the different categories of problems that they might develop. More precisely, we aimed to identify the main factors that explain the probability of having health-, leisure/social, and work-related problems due to the informal services provided to dependent patients with COPD.

\section{Methods}

\section{Data collection}

Data was collected by the Survey on Disabilities, Personal Autonomy, and Dependency Situations (Encuesta sobre Discapacidad, Autonomía personal y Situaciones de Dependencia [EDAD]-2008) ${ }^{13}$ conducted by the National Institute of Statistics in Spain. The EDAD-2008 survey investigated the subjective perception that people have about their limitations, the cause of these limitations, its severity, and the aid received. The two-step survey comprised several questionnaires. In Phase 1, an initial home questionnaire was done to identify families/households having a member with disabilities. In Phase 2, people with disabilities and their families were interviewed using different questionnaires, including a questionnaire on disabilities for individuals aged 6 or more years, a questionnaire on limitations of children from 0 to 5 years of age, and a questionnaire addressed to primary caregivers. The information was obtained between November 2007 and February 2008. The survey examined a representative sample of the disabled population at the national and the regional level. The full methodological process can be found at the following link: http://www.ine. es/metodologia/t15/t1530418.pdf.

The population studied included disabled individuals residing in a household in Spain and comprised 96,000 households, yielding 260,000 individuals initially interviewed. Of the total sample, 22,795 persons with disabilities were identified and interviewed in depth. Personal interviews were used to collect all the data; in exceptional cases, these data were complemented with telephone interviews. We used the elevation factor to extrapolate the results to the entire population with COPD and their caregivers. Informal care was defined as the attention provided by persons who are not professional social workers to an individual with limited autonomy, to help this person perform one or more daily activities.

Among the variables included in the EDAD-2008 survey were the personal characteristics of the persons with disabilities and their caregivers; the characteristics of personal care; and the problems caused by informal caregiving, divided along three different dimensions: health, occupation, and family and social relationships. Regarding health-related problems, we analyzed whether the caregivers felt tired, depressed, required treatment due to the care provided, or had other health problems. In relation to occupation-related problems, we considered whether caregivers had to give up their job, had reduced their working hours, had problems with their work schedule, deterioration of their work life, or had economic problems. Finally, with respect to leisure/ social problems, we analyzed whether caregivers had to reduce their leisure time, were not able to go on holidays, had less time for self-care or for friends, or had problems with their partners.

EDAD-2008 is a rich dataset. It contains several questions similar to the included in the Spanish Official Scale for assessing the grade of dependence and for classifying people with limited autonomy by level of severity. This enabled to estimate the grade of dependence of the people interviewed in a similar manner to that applied in the Official Scale. The Official Scale is based on a questionnaire as well as on direct observation of the dependent candidate by a qualified professional. For the case of people with intellectual or cognitive impairment, an informed proxy respondent must answer the questionnaire. The determination of the degree of dependence takes into account medical reports and the use of prostheses. The Official Scale considers 47 tasks grouped into ten activities (eating and drinking, control of physical needs, bathing and hygiene, other physical care, dressing and undressing, maintaining one's health, mobility, moving 
inside the home, moving outside the home, and housework). This scheme establishes four degrees of support: supervision (if the dependent only needs another person to prepare the elements necessary to perform the activity), partial physical attention (when the other person has to participate actively), maximum physical attention (if the person has to substitute the dependent individual in performing the activity), and special attention (the dependent individual has behavior disorders that hinder performance of the task by the other person). The final score is the sum of the weights of the tasks for which the individual has difficulty, multiplied by the degree of supervision required and the weight assigned to that activity, as proposed by the Spanish Ministry of Work and Social Affairs. ${ }^{14}$ The degree of dependence is graded as follows: (1) moderate dependence, where the person needs help to perform several basic activities of daily life at least once per day and also needs intermittent or limited support for his/her personal autonomy; (2) severe dependence, where the person needs help to perform several basic activities of daily life two or three times per day but does not require the continued support from a caregiver nor have extensive support needs for his/ her personal autonomy; and (3) great dependence, where the person needs help to perform several basic activities of daily living several times per day and needs essential and continued support from another person due to the total loss of physical, mental, intellectual, or sensorial autonomy.

To put our results into perspective, the results obtained for caregivers of COPD patients were compared with those related to caregivers of individuals with other chronic diseases, such as cancer, stroke, acute myocardial infarction, and mental illness, obtained from the same source of data.

\section{Statistical analysis}

The caregivers were asked whether they had experienced any problems arising from the provision of care (yes $=1$; no $=0$ ). Several statistical analyses were carried out to estimate the marginal impact that a one-degree increase in the level of dependence would have on the problems supported by caregivers. For this purpose, we designed some probit models to estimate the probability of a problem occurring in health, occupational, and social dimensions.

The specifications of the model were as follows:

$$
y^{*}=\beta^{\prime} x+\varepsilon
$$

in which $\mathrm{y}^{*}$ is not observed, $\mathrm{X}$ represents a vector of explanatory variables, $\beta$ is a vector of the parameters, and $\varepsilon$ is the standard error.

$$
\begin{aligned}
\operatorname{Prob}\left(\mathrm{HP}_{\mathrm{i}}\right)= & \beta_{\mathrm{H} 0}+\beta_{\mathrm{H} 1} \mathrm{X}_{1}+\beta_{\mathrm{H} 2} \mathrm{X}_{2}+\beta_{\mathrm{H} 3} \mathrm{X}_{3}+\beta_{\mathrm{H} 4} \mathrm{X}_{4} \\
& +\beta_{\mathrm{H} 5} \mathrm{X}_{5}+\beta_{\mathrm{H} 6} \mathrm{X}_{6}+\beta_{\mathrm{H} 7} \mathrm{X}_{7}+\beta_{\mathrm{H} 8} \mathrm{X}_{8} \\
& +\beta_{\mathrm{H} 9} \mathrm{X}_{9}+\beta_{\mathrm{H} 10} \mathrm{X}_{10}+\beta_{\mathrm{H} 11} \mathrm{X}_{11}+\mathrm{u}_{\mathrm{i}}
\end{aligned}
$$

$$
\begin{aligned}
\operatorname{Prob}\left(\mathrm{PP}_{\mathrm{i}}\right)= & \beta_{\mathrm{P} 0}+\beta_{\mathrm{P} 1} \mathrm{X}_{1}+\beta_{\mathrm{P} 2} \mathrm{X}_{2}+\beta_{\mathrm{P} 3} \mathrm{X}_{3}+\beta_{\mathrm{P} 4} \mathrm{X}_{4} \\
& +\beta_{\mathrm{P} 5} \mathrm{X}_{5}+\beta_{\mathrm{P} 6} \mathrm{X}_{6}+\beta_{\mathrm{P} 7} \mathrm{X}_{7}+\beta_{\mathrm{P} 8} \mathrm{X}_{8} \\
& +\beta_{\mathrm{P} 9} \mathrm{X}_{9}+\beta_{\mathrm{P} 10} \mathrm{X}_{10}+\beta_{\mathrm{P} 11} \mathrm{X}_{11}+\mathrm{u}_{\mathrm{i}}
\end{aligned}
$$

$\operatorname{Prob}\left(\mathrm{LP}_{\mathrm{i}}\right)=\beta_{\mathrm{L} 0}+\beta_{\mathrm{L} 1} \mathrm{X}_{1}+\beta_{\mathrm{L} 2} \mathrm{X}_{2}+\beta_{\mathrm{L} 3} \mathrm{X}_{3}+\beta_{\mathrm{L} 4} \mathrm{X}_{4}$

$$
\begin{aligned}
& +\beta_{\mathrm{L} 5} \mathrm{X}_{5}+\beta_{\mathrm{L} 6} \mathrm{X}_{6}+\beta_{\mathrm{L} 7} \mathrm{X}_{7}+\beta_{\mathrm{L} 8} \mathrm{X}_{8} \\
& +\beta_{\mathrm{L} 9} \mathrm{X}_{9}+\beta_{\mathrm{L} 10} \mathrm{X}_{10}+\beta_{\mathrm{L} 11} \mathrm{X}_{11}+\mathrm{u}_{\mathrm{i}}
\end{aligned}
$$

where Prob(HP) represents the probability that a caregiver suffers from health problems, Prob(PP) represents the probability that a caregiver suffers from professional work problems, Prob(LP) represents the probability that a caregiver suffers from leisure/social problems, $X_{1}$ represents the age of the caregiver, $\mathrm{X}_{2}$ the gender of caregiver, $\mathrm{X}_{3}$ educational level of the caregiver, $\mathrm{X}_{4}$ marital status of the caregiver, $\mathrm{X}_{5}$ economic activity of the caregiver, $\mathrm{X}_{6}$ level of income, $\mathrm{X}_{7}$ degree of dependence of the person cared for, $\mathrm{X}_{8}$ size of the municipality in which the patient resides, $\mathrm{X}_{9}$ regions where the patient resides, $X_{10}$ whether patients receive formal inhome care, $\mathrm{X}_{11}$ whether patients receive formal out-home care, the betas are the regressors of each model and, finally, "u"s are the error terms of each equations.

We repeated this analysis for each category of problems, changing the dependent variable for each type of problem.

\section{Results}

According to the EDAD-2008 survey, the number of people aged 6 years or older living at home with one or more disabilities and with COPD totaled 461,884, representing a prevalence of 100.44/10,000 (the population of Spain in July 2008 was 45,983,169 inhabitants ${ }^{11}$ (mean age of 69.4 years; $57.5 \%$ female). Regarding the level of dependence, $64.4 \%$ were classified as nondependent, $14.5 \%$ as having moderate dependence, $10.1 \%$ as severe dependence, and $11 \%$ as great dependence (Table 1). Furthermore, the most frequent disabilities were those related to mobility $(74.9 \%)$, performing housework (62.5\%), and self-care $(58.7 \%)$. The least frequent problems were those related to audition (30.6\%), vision (30.1\%), communication (18.3\%), learning (14.1\%), and interaction (13.5\%). On average, people with COPD presented disabilities in three of the previous 8 domains.

Up to $66.3 \%$ of COPD patients received personal care due to their disability, with the main caregivers being relatives or friends (informal care) in $88.6 \%$ of cases. It was estimated that 220,892 people were informal caregivers providing care 
Table I Characteristics of patients with COPD and disabilities and those of their informal caregivers

\begin{tabular}{|c|c|c|c|}
\hline & $\begin{array}{l}\text { People with COPD } \\
\text { (population }=461,884) *\end{array}$ & $\begin{array}{l}\text { People with COPD who } \\
\text { received informal care } \\
\text { (population }=220,892 \text { )* }\end{array}$ & $\begin{array}{l}\text { Primary informal } \\
\text { caregivers }(* *) \\
(\text { population }=220,892) *\end{array}$ \\
\hline Age, mean (SD) & $69.4(17.1)$ & $72.0(18.9)$ & $56.5(14.9)$ \\
\hline \multicolumn{4}{|l|}{ Sex } \\
\hline Male & 42.5 & 41.8 & 23.9 \\
\hline Female & 57.5 & 58.2 & 76.1 \\
\hline \multicolumn{4}{|l|}{ Marital status } \\
\hline Married & 66.8 & 48.7 & 69.3 \\
\hline Single & 19.6 & 13.1 & 18.2 \\
\hline Widowed & 7.8 & 35.9 & 6.2 \\
\hline Separated/divorced & 5.8 & 2.3 & 6.3 \\
\hline \multicolumn{4}{|l|}{ Educational level } \\
\hline Illiterate or primary school incomplete & 44.9 & 59.1 & 29.2 \\
\hline Primary or equivalent & 29.3 & 27.4 & 33.9 \\
\hline Secondary school/middle level professional & 20.3 & 11.3 & 30.1 \\
\hline University degree or equivalent & 5.5 & 2.2 & 6.8 \\
\hline Level of dependence & & & - \\
\hline Nondependent & 64.4 & 33.6 & - \\
\hline Moderate dependence & 14.5 & 25.9 & - \\
\hline Severe dependence & 10.1 & 18.7 & - \\
\hline Great dependence & 11.0 & 21.8 & - \\
\hline \multicolumn{4}{|c|}{ Average hours of caregiving provided per day, mean (SD) } \\
\hline Nondependent & & & $6.7(8.1)^{* * *}$ \\
\hline Moderate dependence & & & $8.8(11.7)^{* * *}$ \\
\hline Severe dependence & & & $11.8(15.5)^{* * *}$ \\
\hline Great dependence & & & I $2.7(\mid 7.0)^{* * *}$ \\
\hline
\end{tabular}

Notes: Authors' extract based on data from the EDAD 2008 survey. ${ }^{13}$ Data are expressed in percentages unless otherwise specified. *Data extrapolated to entire population with COPD. **Caregivers providing at least I hour of care per day. ***Daily hours without restriction.

Abbreviations: EDAD, Encuesta sobre Discapacidad, Autonomía personal y Situaciones de Dependencia (Survey on Disabilities, Personal Autonomy, and Dependency Situations); SD, standard deviation.

to patients with COPD and that $76.1 \%$ were females, with a mean age of 56.5 years.

Many informal caregivers had a heavy workload as a result of caregiving. Up to $35.4 \%$ recognized having healthrelated problems; $82.9 \%$ had social/leisure time problems; and among those who were younger than 65 years, $37.3 \%$ had occupation-related problems (Table 2). Among health-related problems, feeling tired was the most frequent, followed by feeling depressed. In most cases, the level of dependence was associated with a higher percentage of caregivers with health problems. Among caregivers of patients with great dependence, $78.4 \%$ felt tired and $51.9 \%$ felt depressed (Table 2).

In regard to leisure problems, again, the higher the level of dependence, the higher the frequency of problems in caregivers. Among caregivers who cared for patients with great dependence, $82.9 \%$ had to decrease their leisure time, $66.2 \%$ were not able to go on holidays, $12.4 \%$ had conflicts with their partner, $65.1 \%$ had no time for friends, and $58.4 \%$ had no time for self-care. Even for nondependent patients, we observed that $40.5 \%$ caregivers reported a decrease in leisure time, and $25.8 \%$ were not able to go on holidays (Table 2).

Finally, among caregivers who were younger than 65 years and cared for patients with great dependence, $18.2 \%$ had to give up their job and up to $35.2 \%$ could not work out of home (Table 2).

Table 3 shows the comparison of the burden of informal care caused by COPD or by other chronic diseases, such as cancer, stroke, acute myocardial infarction, or mental illness. The percentage of caregivers of COPD patients presenting deterioration in health was quite similar to that of caregivers of patients with myocardial infarction, mental illness, or cancer $(35.4 \%$ versus $35.5 \%, 36.4 \%$, and $33.6 \%$, respectively). However, the number of caregivers reporting deterioration in health was higher in stroke patients $(45.9 \%)$. Caregivers who cared for stroke patients more frequently described leisure problems $(70.1 \%$ had reduced their leisure time), followed by those giving care to patients myocardial infarction (61\%), mental illness (60.5\%), COPD (59.5\%), and cancer $(58.9 \%)$. 
Table 2 Percentage of informal caregivers of patients with COPD with health-, professional-, and leisure/social-related problems

\begin{tabular}{|c|c|c|c|c|c|}
\hline & $\begin{array}{l}\text { Great dependence } \\
\text { (population }=48,154)^{*}\end{array}$ & $\begin{array}{l}\text { Severe dependence } \\
\text { (population }=41,307) *\end{array}$ & $\begin{array}{l}\text { Moderate dependence } \\
\text { (population }=57,2 \mathrm{II} \text { )* }\end{array}$ & $\begin{array}{l}\text { Nondependent } \\
\text { (population }=\mathbf{7 4 , 2 2 0} \text { )* }\end{array}$ & Total** \\
\hline \multicolumn{6}{|l|}{ Health-related problems } \\
\hline Global & 62.1 & 43.3 & 30.8 & 19.6 & 35.4 \\
\hline Treatment & 34.9 & 18.7 & 15.7 & 8.7 & 17.6 \\
\hline Feels tired & 78.4 & 62.1 & 47.9 & 31.8 & 50.8 \\
\hline Feels depressed & 51.9 & 37.5 & 29.6 & 17.6 & 31.2 \\
\hline Other health-related problems & 12.0 & 8.2 & 6.9 & 8.5 & 8.7 \\
\hline \multicolumn{6}{|c|}{ Leisure/social-related problems } \\
\hline Global & 27.3 & 21.1 & 25.7 & 25.7 & 82.9 \\
\hline Decreased leisure time & 82.9 & 71.2 & 57.4 & 40.56 & 59.5 \\
\hline Decreased holiday time & 66.2 & 57.5 & 46.6 & 25.8 & 45.5 \\
\hline Conflict with partner & 12.4 & 5.1 & 5.9 & 5.1 & 6.8 \\
\hline Time with friends & 65.1 & 52.7 & 35.5 & 20.9 & 40.0 \\
\hline Time with family & 2.7 & 3.4 & 6.9 & 3.2 & 4.0 \\
\hline Self-care time & 58.4 & 35.1 & 26.8 & 17.2 & 31.7 \\
\hline \multicolumn{6}{|l|}{ Professional-related problems*** } \\
\hline Global & 30.6 & 20.5 & 24.4 & 24.3 & 37.3 \\
\hline Abandon job & 18.2 & 13.7 & 9.7 & 7.4 & 11.5 \\
\hline Cannot work out of home & 35.2 & 27.0 & 21.6 & 13.5 & 22.7 \\
\hline Decreased working time & 12.0 & 6.8 & 7.3 & 5.8 & 7.7 \\
\hline Deterioration of working life & 15.5 & 9.4 & 11.5 & 6.9 & 10.3 \\
\hline $\begin{array}{l}\text { Having problems with work } \\
\text { schedule }\end{array}$ & 17.8 & 12.0 & 8.7 & 5.3 & 10.1 \\
\hline Economic problems & 28.2 & 24.0 & 18.8 & 11.6 & 19.3 \\
\hline
\end{tabular}

Notes: Authors' extract based on data from the EDAD 2008 survey. ${ }^{13}$ *Estimated population using elevation factors provided by EDAD-2008. **Figures estimated taking into account the total number of informal caregivers. ***Only informal caregivers younger than 65 years old.

Abbreviation: EDAD, Encuesta sobre Discapacidad, Autonomía personal y Situaciones de Dependencia (Survey on Disabilities, Personal Autonomy, and Dependency Situations).

Probit models were made to estimate the probability of a problem related to health, work, and social dimensions in caregivers, with the results showing an increase in this probability according to the degree of dependence of the person cared for. For example, caring for a person with moderate dependence was associated with a marginal effect of 0.102 , that is, the risk of developing a health problem was $10.2 \%$ greater in caregivers of a COPD patient with moderate dependence, $21.6 \%$ greater in caregivers of a patient with severe dependence, and $39.3 \%$ greater in those caring for a patient with great dependence (Table 4). Similar results were obtained for the individual health-related problems of caregivers (need for treatment, feeling tired, feeling depressed, and other health problems) (Table 4), for occupation-related problems (Table 5), and for leisure/social problems (Table 6).

\section{Discussion}

The results of our study demonstrate that there is an important workload involved in the informal care of people with COPD. This workload has a clear impact on the health, occupational, and social environment of caregivers. Indeed,
$82.9 \%$ of the caregivers reported having social problems due to the informal services provided, $35.4 \%$ had health-related problems, and among those who were younger than 65 years, almost 38\% had occupation-related problems.

COPD is a debilitating chronic disease that affects up to $10 \%$ of the individuals older than 40 years. ${ }^{15}$ This high prevalence implicates a large burden to the families, friends, and society. ${ }^{5}$ An American study using data from the Health and Retirement Study demonstrated that COPD was associated with a decrease in the likelihood of employment of $8.6 \%$, being similar to that seen with stroke and greater than that seen with heart disease, cancer, hypertension, and diabetes. ${ }^{16}$ Informal caregivers are of major importance in COPD, since most home care is provided by family and friends. In fact, more than $70 \%$ of COPD patients have one or more informal caregiver. ${ }^{17}$

Caregivers have a strong impact on the well-being of a patient with COPD. Some studies have identified that having an informal caregiver was associated with better adherence to treatment, a reduced rate of smoking, and less frequent emergency visits compared with those for patients living alone. ${ }^{18,19}$ 


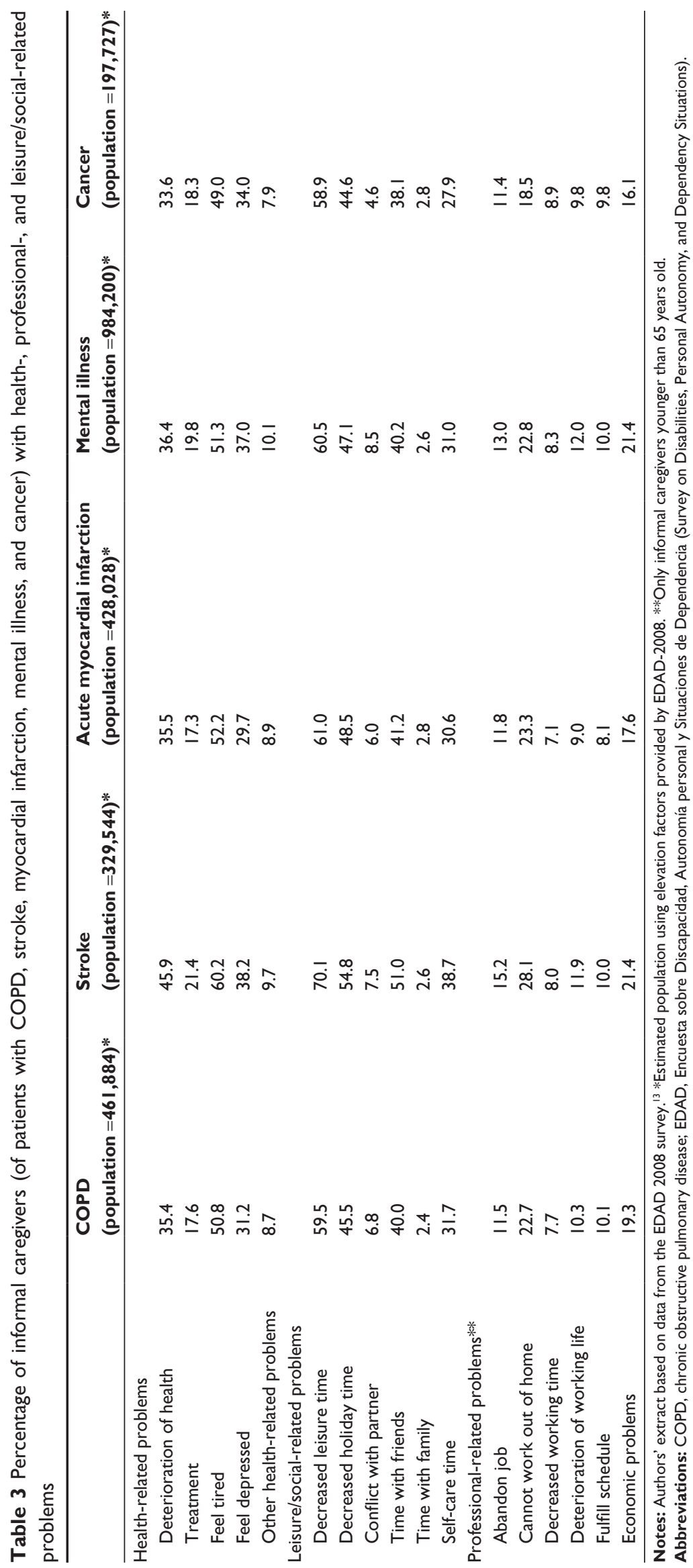



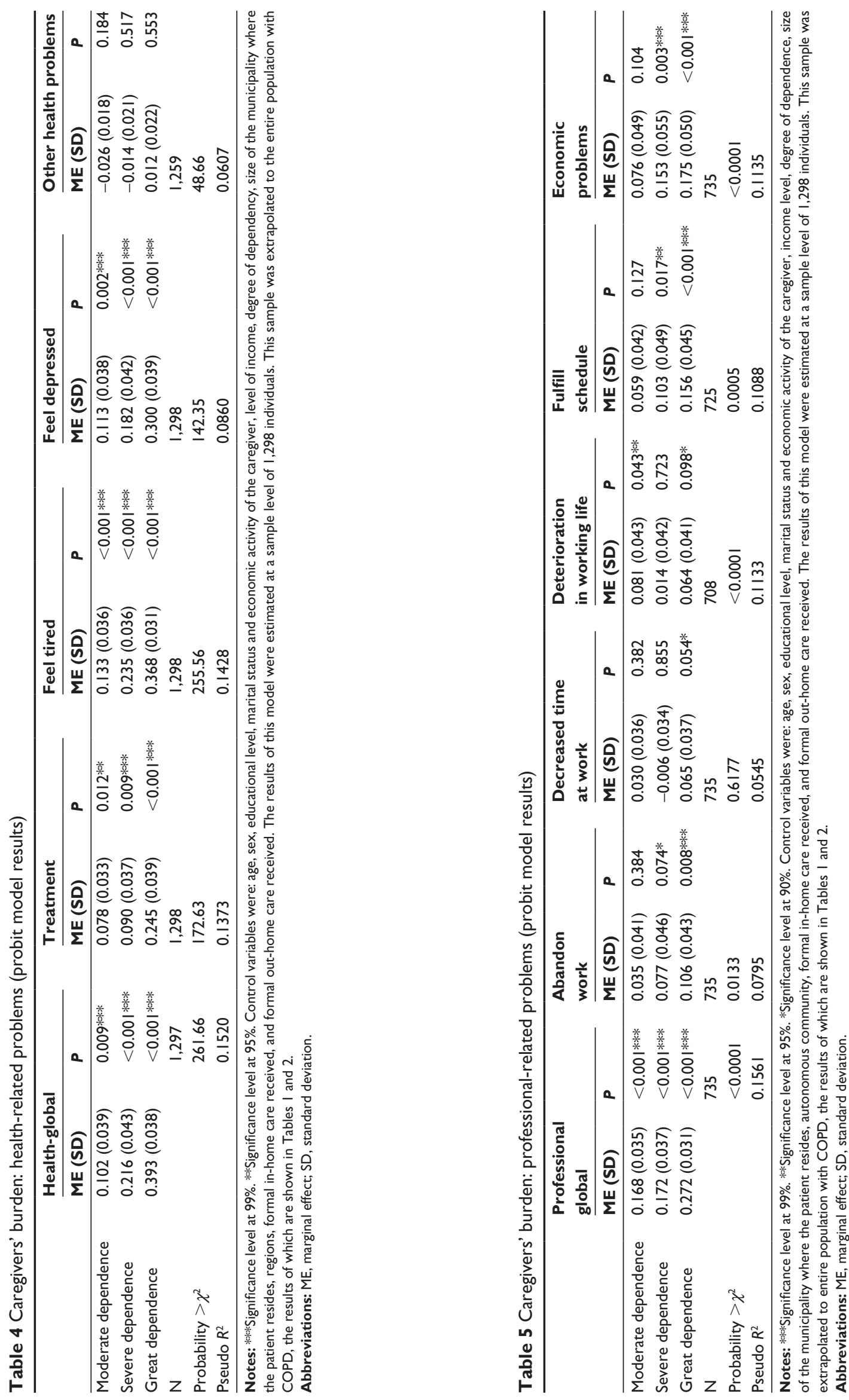


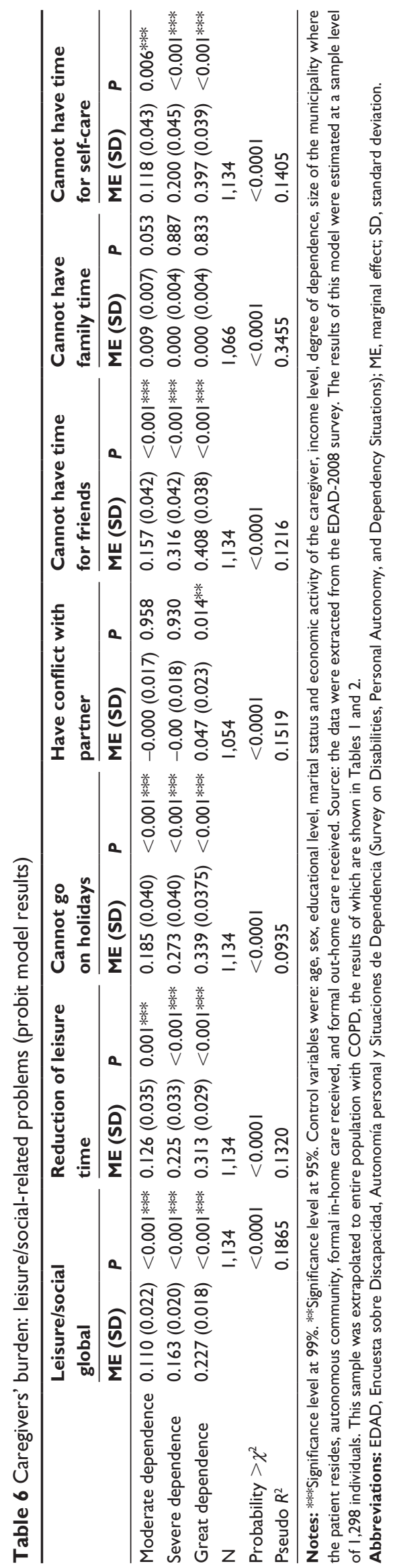

However, the impact on health, social, and occupational aspects of caregivers of patients with COPD has not been extensively studied, and only a few articles have addressed this important issue. Informal caregivers may experience anxiety, helplessness, depression, uncertainty about the future, and social isolation, among others. ${ }^{17,20}$ A study carried out in Brazil observed that $85 \%$ of caregivers of patients with COPD were female with a mean age of 51 years, and most had low levels of income and schooling. ${ }^{21}$ The impact of COPD on the quality of life of caregivers has also been investigated in several studies. Lee et $\mathrm{al}^{22}$ showed that the main problems described by informal caregivers were depression and anxiety. Cain and Wicks ${ }^{11}$ showed that black caregivers experienced less burden than did their white counterparts, and caregivers younger than 55 years of age reported greater burden than did older caregivers. Similar levels of burden were described in male versus female and spouse versus nonspouse caregivers. Other studies have analyzed the main factors that might have a significant association with the burden of caregiving in COPD patient. Pinto et $\mathrm{a}^{21}$ stressed that caregiving in COPD causes a significant impact on the quality of life of caregivers and that the most important predictor of COPD burden was the relationship between caregivers and patients.

We divided our analysis into different aspects of the life of caregivers. Regarding health-related problems, feeling tired was the most frequent, followed by feeling depressed, similar to the findings in the previous study by Lee et al..$^{22}$ In relation to leisure problems, having to reduce leisure time, not being able to go on holidays, and difficulty in seeing friends were the most prevalent problems. Interestingly, among caregivers who were younger than 65 years, most described not being able to work out of the home or having economic problems due to the informal services provided. This finding highlights the large economic burden of COPD that extends beyond the high direct costs of the disease itself. ${ }^{13,23}$

The probability of a problem arising in an informal caregiver was positively associated with the degree of dependence of the COPD patient receiving care. Furthermore, the likelihood of developing health problems was higher among caregivers of patients with great, severe, or moderate dependence than among those caring for nondependent patients. With respect to leisure/social problems, the degree of dependence was also associated with the probability of not being able to go on holidays, having conflict with a partner (only in the highest level of dependence), and not having time for friends and for self-care. To our knowledge, no previous study has evaluated the risk of caregivers developing 
problems according to the degree of dependence of the COPD patients. However, Figueiredo et $\mathrm{al}^{24}$ demonstrated that caring for people with advanced COPD reported higher subjective burden, more depression, and poorer self-rated mental health than did those caring for people with early COPD and suggested the importance of early interventions in the context of COPD, to prevent the burden of caregivers. Among caregivers younger than 65 years, the probability of presenting work-related problems increased to $16.8 \%$, $17.2 \%$, and $27.2 \%$ in caring for patients with moderate, severe, or great dependence, respectively (compared with nondependent subjects). The age of the caregivers may not influence care behavior, but older caregivers described significantly lower COPD-related knowledge than did the younger caregivers, and therefore, more education on the use of drugs in COPD and the prevention of COPD symptoms is needed in these caregivers. ${ }^{25}$

The importance of the social services provided by informal caregivers to COPD patients can be seen when comparing the burden of caregiving provided by relatives and friends in people with COPD with that of caregivers of patients with other chronic illness, such as cancer, stroke, acute myocardial infarction, or mental illness, Caregivers of COPD patients reported similar problems (health, occupational, and leisure/social problems) to those of caregivers of patients with myocardial infarction, cancer, or mental illness. Only caregivers of stroke patients presented a somewhat higher associated burden than that of caregivers of patients with COPD.

Several limitations of the study should be pointed out. First of all, the survey did not include data on lung function, and therefore, it is not possible to confirm the spirometric criteria for COPD. Secondly, even though the EDAD2008 provides a wealth of information related to disabled people and their caregivers, the data is cross-sectional and not longitudinal. Consequently, it is not possible to study the impact of a new diagnosis of COPD on the lives of a person and their family. Similarly, since it is not possible to establish the causal relationships between the illnesses and the burden of caregiving, the figures for the burden of caregiving (expressed in the three dimensions considered) cannot be interpreted as being caused exclusively by COPD since other diseases (morbidity) could affect the number of care hours received. It is well recognized that elderly patients with COPD often have associated comorbid diseases that influence the health status, ${ }^{26}$ although this is not different from the situation of elderly individuals with other chronic diseases.

\section{Conclusion}

The results of this study stress the importance of efforts to improve support for caregivers of patients with COPD. Indeed, the stress of caregivers related to the specific demands of patients with chronic disease such as COPD is already known. However, little research has been done regarding the needs of caregivers of COPD patients or related to interventions to assist these people in providing care, ${ }^{8}$ and thus, more qualitative research is needed to understand the impact of caring for patients with COPD. ${ }^{27}$ This knowledge is critical to ensure that caregivers receive the information they need to carry out their role while maintaining their own physical and emotional health. The development of strategies to mitigate these problems would protect the support network of the persons cared for.

\section{Acknowledgment}

This study has been funded by an unrestricted grant from Chiesi, Spain.

\section{Disclosure}

The authors report no conflicts of interest in this work.

\section{References}

1. Catalá-López F, Gènova-Maleras R. [Prevention and control of chronic non-communicable diseases in Spain: A call to action]. Med Clin (Barc). 2013;140(11):502-503. Spanish.

2. Roqué I Figuls M, Salvà A, Bolíbar I, Rivero T. [Trends in self-perceived health and chronic disability in the elderly Spanish population: evolution between years 1993 and 2006]. Med Clin (Barc). 2012;139(7):284-289. Spanish.

3. Decramer M, Janssens W, Miravitlles M. Chronic obstructive pulmonary disease. Lancet. 2012;379(9823):1341-1351.

4. National Statistics Institute. Death Statistic according to Cause of Death. 2014. Available from: http://www.ine.es/jaxi/menu. do?type $=$ pcaxis $\&$ path $=\% 2 \mathrm{Ft} 15 / \mathrm{p} 417 \&$ file $=$ inebase $\& \mathrm{~L}=0$. Accessed May 17, 2014. Spanish.

5. Chapman KR, Mannino DM, Soriano JB, et al. Epidemiology and costs of chronic obstructive pulmonary disease. Eur Respir J. 2006;27(1): 188-207.

6. Miravitlles M, Calle M, Alvarez-GutierrezF, Gobartt E, LópezF, Martín A. Exacerbations, hospital admissions and impaired health status in chronic obstructive pulmonary disease. Qual Life Res. 2006;15(3):471-480.

7. Miravitlles M, Anzueto A, Legnani D, Forstmeier L, Fargel M. Patient's perception of exacerbations of COPD - the PERCEIVE study. Respir Med. 2007;101(3):453-460.

8. Caress AL, Luker KA, Chalmers KI, Salmon MP. A review of the information and support needs of family carers of patients with chronic obstructive pulmonary disease. J Clin Nurs. 2009;18(4):479-491.

9. Miravitlles M, Cantoni J, Naberan K. Factors associated with a low level of physical activity in patients with chronic obstructive pulmonary disease. Lung. 2014;192(2):259-265.

10. Leidy NK, Traver GA. Adjustment and social behaviour in older adults with chronic obstructive pulmonary disease: the family's perspective. $J$ Adv Nurs. 1996;23(2):252-259.

11. Cain CJ, Wicks MN. Caregivers attributes as correlates of burden in family caregivers coping with chronic obstructive pulmonary disease. J Fam Nurs. 2000;6(1):46-68. 
12. Seamark DA, Blake SD, Seamark CJ, Halpin DM. Living with severe chronic obstructive pulmonary disease (COPD): perceptions of patients and their carers. An interpretative phenomenological analysis. Palliat Med. 2004;18(7):619-625.

13. National Statistics Institute. Survey on Disability, Personal Autonomy and Dependency Situations 2008. Available from: http://www.ine.es/ jaxi $/$ menu.do?type $=$ pcaxis $\&$ path $=\% 2 \mathrm{Ft} 15 / \mathrm{p} 418 \&$ file $=$ inebase $\& \mathrm{~L}=1$. Accessed June 6, 2013. Spanish.

14. Ministerio de Trabajo y Asuntos Sociales. Real Decreto 504/2007, de 20 de Abril, por el que Se Aprueba el Baremo de Valoración de la Situación de Dependencia Establecido por la Ley 39/2006, de 14 de Diciembre, de Promoción de la Autonomía Personal y Atención a las Personas en Situación de Dependencia. [Ministry of Labour and Social Affairs. Royal Decree 504/2007, of 20 April, approving the Offical Scale of Assessment of Dependent Established by 39/2006 of December 14th Law of Promotion of Personal Autonomy and Care for Dependent People] Madrid: Agencia Estatal Boletín Oficial del Estado; 2007. Available from: http://www.boe.es/boe/dias/2007/04/21/pdfs/ A17646-17685.pdf. Accessed May 17, 2014. Spanish.

15. Miravitlles M, Soriano JB, García-Río F, et al. Prevalence of COPD in Spain: impact of undiagnosed COPD on quality of life and daily life activities. Thorax. 2009;64(10):863-868.

16. Thornton Snider J, Romley JA, Wong KS, Zhang J, Eber M, Goldman DP. The disability burden of COPD. COPD. 2012;9(5):513-521.

17. Gautun H, Werner A, Lurås H. Care challenges for informal caregivers of chronically ill lung patients: results from a questionnaire survey. Scand J Public Health. 2012;40(1):18-24.

18. Trivedi RB, Bryson CL, Udris E, Au DH. The influence of informal caregivers on adherence in COPD patients. Ann Behav Med. 2012;44(1): $66-72$.
19. Wakabayashi R, Motegi T, Yamada K, Ishii T, Gemma A, Kida K. Presence of in-home caregiver and health outcomes of older adults with chronic obstructive pulmonary disease. J Am Geriatr Soc. 2011; 59(1):44-49.

20. Giacomini M, DeJean D, Simeonov D, Smith A. Experiences of living and dying with COPD: a systematic review and synthesis of the qualitative empirical literature. Ont Health Technol Assess Ser. 2012; 12(13): $1-47$.

21. Pinto RA, Holanda MA, Medeiros MM, Mota RM, Pereira ED. Assessment of the burden of caregiving for patients with chronic obstructive pulmonary disease. Respir Med. 2007;101(11):2402-2408.

22. Lee E, Lum CM, Xiang YT, Ungvari GS, Tang WK. Psychosocial condition of family caregivers of patients with chronic obstructive pulmonary disease in Hong Kong. East Asian Arch Psychiatry. 2010;20(4): $180-185$.

23. Miravitlles M, Murio C, Guerrero T, Gisbert R. Costs of chronic bronchitis and COPD. A 1-year follow-up study. Chest. 2003;123(3):784-791.

24. Figueiredo D, Gabriel R, Jácome C, Cruz J, Marques A. Caring for relatives with chronic obstructive pulmonary disease: how does the disease severity impact on family carers? Aging Ment Health. 2014; 18(3):385-393.

25. Hsiao PC, Chu CM, Sung PY, Perng WC, Wang KY. Differences in COPD patient care by primary family caregivers: an age-based study. PLoS One. 2014;9(9):e107870.

26. Barnes PJ, Celli BR. Systemic manifestations and comorbidities of COPD. Eur Respir J. 2009;33(5):1165-1185.

27. Grant M, Cavanagh A, Yorke J. The impact of caring for those with chronic obstructive pulmonary disease (COPD) on carers' psychological well-being: a narrative review. Int J Nurs Stud. 2012;49(11): 1459-1471.
International Journal of COPD

\section{Publish your work in this journal}

The International Journal of COPD is an international, peer-reviewed journal of therapeutics and pharmacology focusing on concise rapid reporting of clinical studies and reviews in COPD. Special focus is given to the pathophysiological processes underlying the disease, intervention programs, patient focused education, and self management protocols.

\section{Dovepress}

This journal is indexed on PubMed Central, MedLine and CAS. The manuscript management system is completely online and includes a very quick and fair peer-review system, which is all easy to use. Visit $\mathrm{http}: / / \mathrm{www}$.dovepress.com/testimonials.php to read real quotes from published authors. 